\title{
Burden of Stroke in Myanmar
}

\author{
Narayanaswamy Venketasubramanian ${ }^{\mathrm{a}}$ Yee Mon Khine ${ }^{\mathrm{b}}$ Ohnmar Ohnmar ${ }^{\mathrm{b}}$ \\ Myat Po Po Kyaw Khin ${ }^{c}$ Min Thit Win ${ }^{b}$ \\ ${ }^{a}$ Raffles Neuroscience Centre, Raffles Hospital, Singapore, Singapore; ${ }^{b}$ Department of Neurology, Yangon General \\ Hospital/University of Medicine 1, Yangon, Myanmar/Burma; ' Department of Neurology, Yangon General Hospital, \\ Yangon, Myanmar/Burma
}

\section{Keywords}

Cerebrovascular disease $\cdot$ Stroke $\cdot$ Burden · Myanmar

\begin{abstract}
Myanmar is home to over 51 million people. The age- and sex-standardized mortality rate due to stroke is 165.4/100,000, while the rate of age- and sex-standardized disability-adjusted life years lost due to stroke is $2971.3 / 100,000$. The prevalence of stroke among adults aged 40-99years is 1.5\%. Stroke is the leading cause of morbidity and mortality and comprises $20 \%$ of the neurological workload. There are only 10 stroke units in the whole country. Doctors are aware of the importance of hypertension in stroke prevention and the need for physiotherapy after stroke, but, until recently and in rural areas, they also tend to use steroids and neuroprotectants, and lower blood pressure aggressively acutely after stroke; antiplatelets are not widely used. Thrombolysis service is available at some tertiary centers but mechanical thrombectomy is not yet available.

(c) 2021 The Author(s)

Published by S. Karger AG, Basel
\end{abstract}

karger@karger.com www.karger.com/cee

Karger $\stackrel{\text { ' }}{=}$

GOPEN ACCESS
(C) 2021 The Author(s)

Published by S. Karger AG, Basel

This is an Open Access article licensed under the Creative Common Attribution-NonCommercial-4.0 International License (CC BY-NC) (http://www.karger.com/Services/OpenAccessLicense), applicable to the online version of the article only. Usage and distribution for commercial purposes requires written permission.
The Republic of the Union of Myanmar, with an area of $676,578 \mathrm{~km}^{2}$ and a population of $>51$ million, is situated in southeast Asia, bounded on the north by the Tibet Autonomous Region of China, on the east by China, Laos, and Thailand, on the south by the Andaman Sea and the Bay of Bengal, and on the west by the Bay of Bengal, Bangladesh, and India [1]. Due to its heterogeneous society consisting of 135 ethnic groups, its large population, and its large area, there are many obstacles to the provision of health services to the whole nation.

\section{Healthcare Services}

The 1,056 public hospitals, with 56,748 beds in total, provide mainly curative and rehabilitative services [2]. There are 87 primary and secondary health centers, 348 maternal and child health centers, 1,684 rural health centers, and 80 school health teams that are mainly responsible for preventive services and public health activities. There are 16 traditional medicine hospitals and 243 traditional medicine clinics. There are also 193 private hospitals, 201 private specialist clinics, and 3,911 private general clinics. The many charity hospitals run by the private

Correspondence to:

Narayanaswamy Venketasubramanian, drnvramani@gmail.com 


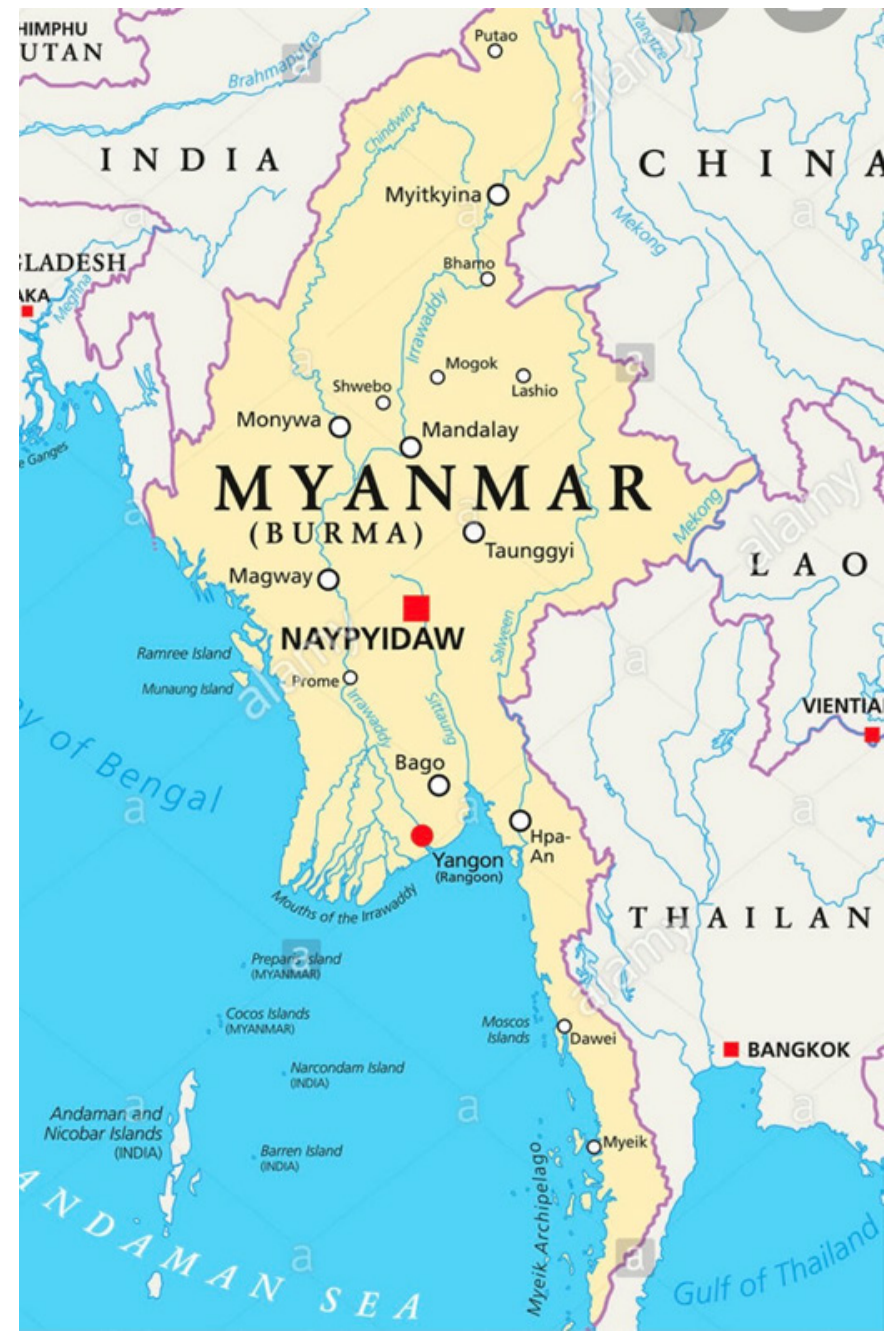

Fig. 1. Neurological care services in Myanmar. Red: Yangon General Hospital, North Okkalapa General Hospital, Defense Services Medical Academy; Orange: Naypyitaw General Hospital; Green: Mandalay General Hospital.

sector cater to the poor. While governmental allocation of funds to the health sector is being increased, the percentage of out-of-pocket expenditures is still high. Health insurance policies are recently available for purchase but are underutilized.

\section{Stroke and Vascular Risk Factor Burden}

The age and sex-standardized mortality rate due to stroke is $165.4 / 100,000$, while the rate of age and sex-standardized disability-adjusted life years lost due to stroke is 2,971.3/100,000 [3]. These rates are higher than in most other countries in southeast Asia. The prevalence of stroke among adults aged $40-99$ years is $1.5 \%$ [4]. Stroke is one of the leading causes of mortality according to the Ministry report [5], and of morbidity and mortality according to the annual reports of the largest hospital, the Yangon General Hospital (YGH), Myanmar.

The high frequency of stroke has been attributed to hypertension due to eating very salty food and the high use of monosodium glutamate [5]. The age-standardized proportion of adults aged $\geq 18$ years with systolic blood pressure $>140 / 90 \mathrm{~mm} \mathrm{Hg}$ or on medication for raised blood pressure is $24.9 \%$ among males and $24.2 \%$ among females; those with fasting blood sugar $>7.0 \mathrm{mmol} / \mathrm{L}$ or on medication for raised blood glucose constitute 6.9 and $7.9 \%$, respectively [3]. Among adults aged $\geq 25$ years, $5.1 \%$ of males and $7.9 \%$ of females have a fasting total cholesterol $\geq 6.1 \mathrm{mmol} / \mathrm{L}$. Among those aged $\geq 18$ years, the frequency of insufficient exercise $(<5$ times $30 \mathrm{~min}$ of moderate activity per week, $<3$ times 20 min of vigorous activity per week, or the equivalent) is 8.3 and $11.6 \%$, the rate of obesity (i.e., BMI $>30$ ) is 2.0 and $5.5 \%$, and the frequency of smoking among those aged $>15$ years is 31.5 and $6.4 \%$ in males and females, respectively. While the frequency of insufficient physical activity and obesity is lower than most southeast Asian countries, the relatively high frequency of smoking among females is a concern.

\section{Clinical Management}

Stroke comprises $20 \%$ of the workload of neurological disorders among inpatients and outpatients in hospitals [6]. With a population per neurologist of 2.21 million [7], stroke cases are mainly managed by general physicians in urban areas, and general practitioners and health assistants in rural areas.

A survey of hospital-based doctors in 2010 showed a high awareness of hypertension as a preventable risk factor and the importance of early physiotherapy after stroke. However, there was a markedly high use of steroids and neuroprotective agents, as well as rapid normalization of elevated blood pressure, and a low use of antiplatelets for secondary prevention [8]. The first stroke unit was successfully opened at YGH in 2014, and the thrombolysis service became available in 2015 (Fig. 1). Until now, thrombolysis service has extended to 5 government and 5 private hospitals. However, there is no resource and expertise for mechanical thrombectomy yet. The country also does not have a standardized stroke registry. 


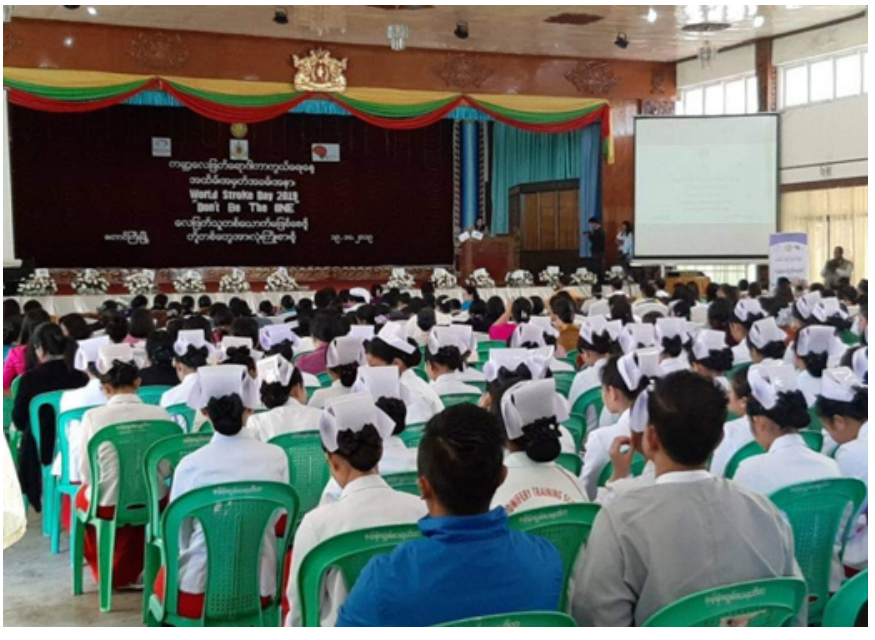

Fig. 2. World stroke day 2019 ceremony at Taunggyi City Hall, Shan State with more than 500 attendees.

\section{Future Trends}

With the gradual aging of the population and the reduction in infectious diseases, the burden of stroke in Myanmar is likely to rise. Detection and control of vascular risk factors and the provision of evidence-based treatments of stroke will be key in controlling this devastating disease. In line with the stroke care needs, the Ministry of Health and Sports, Myanmar, will soon set up a comprehensive stroke care improvement initiative in partnership with the World Health Organization, with the following objectives: establishing a stroke registry, building the capacity of stroke care teams including primary health care workers, developing essential acute stroke and poststroke care package at different levels of health facilities, and initiating community-based stroke rehabilitative services through primary health care teams (Fig. 2, 3).

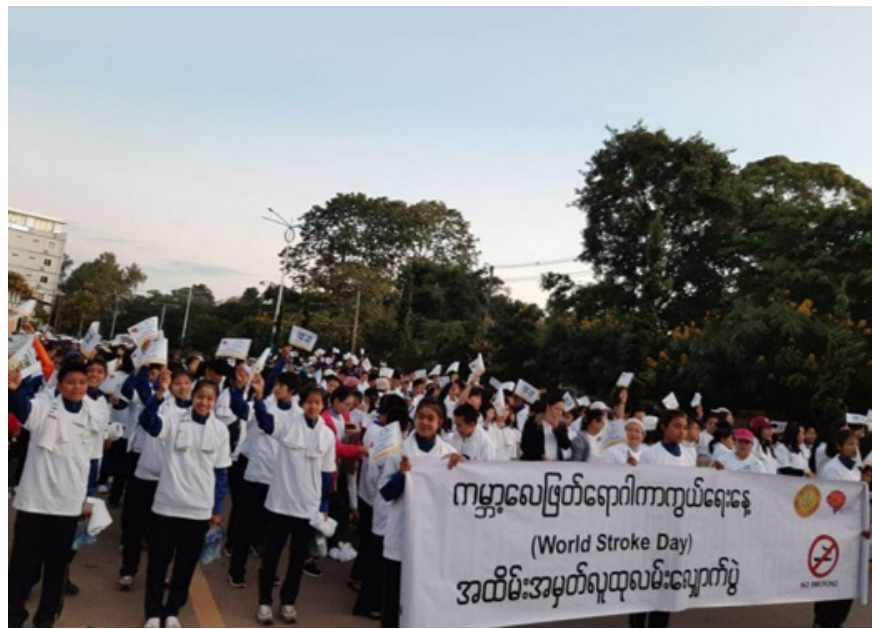

Fig. 3. World Stroke Day 2019 walk by more than 1,200 participants.

\section{Conflict of Interest Statement}

The authors have no conflicts of interest to declare.

\section{Funding Sources}

There was no funding.

\section{Author Contributions}

N.V. conceptualized and wrote the paper; Y.M.K., O.O., and M.P.P.K.K. wrote the paper; M.T.W. conceptualized the paper. All authors performed critical review and approved the final version.

\section{References}

1 [Internet] Myanmar government statistics [cited 10 April 2020]. Available from: https:// www.myanmar.gov.mm/en/governmentwebsite.

2 Latt NN, Myat Cho S, Htun NM, Yu Mon Saw, Myint MN, Aoki F, et al. Healthcare in Myanmar. Nagoya J Med Sci. 2016 May; 78(2):123-34.
3 Venketasubramanian N, Yoon BW, Pandian J, Navarro JC. Stroke Epidemiology in South, East, and South-East Asia: A Review. J Stroke. 2017 Sep;19(3):286-94.

4 Zaw KK, Nwe N, Hlaing SS. Prevalence of cardiovascular morbidities in Myanmar. BMC Res Notes. 2017 Feb;10(1):99.

5 Ministry of Health. Myanmar Health Care System. Health in Myanmar 2014. Nay Pyi Taw, Myanmar: Ministry of Health; 2014. p. 147.
6 Cho MM, Tun N. Profile of neurological practice in Myanmar. Neurol Asia. 2007;12:53-5.

7 Thuy Le MA, Fong SL, Lim KS, Gunadharma S, Sejahtera DP, Visudtibhan A, et al. Underutilization of epilepsy surgery in ASEAN countries. Seizure. 2019 Jul;69:51-6.

8 Kyaw KM, Thu PP. Stroke in Myanmar: attitudes and treatment. Int $J$ Stroke. 2011 Jun;6(3):241-3. 